\title{
Knowledge, attitudes and practices of doctors regarding isoniazid preventive therapy in HIV/AIDS patients at Odi District Hospital, Gauteng province, South Africa
}

\author{
AT Abdulrazaak (D, I Govender* and D Nzaumvila \\ Department of Family Medicine and Primary Health Care, Sefako Makgatho Health Sciences University, Pretoria, \\ Gauteng, South Africa \\ *Corresponding author, email: indiran.govender@gmail.com
}

Introduction: Isoniazid preventive therapy (IPT) can reduce the overall risk of active tuberculosis (TB) in people living with HIV/ AIDS (PLHIV) by up to $62 \%$. As a result the World Health Organization (WHO) and the Joint United Nations Programme on HIV/ AIDS (UNAIDS) have recommended IPT provision as a global strategy to reduce the prevalence of TB for PLHIV. However, whilst there are 84 countries supporting the provision of IPT in their policies, less than 1\% of PLHIV in those countries are currently receiving IPT. Approximately $65 \%$ of TB patients in South Africa are HIV co-infected. Despite this fact, doctors are hesitant to prescribe IPT to TB-negative HIV-infected patients. Many doctors are also unaware of the current IPT guidelines of South Africa. This study sought to determine the level of knowledge, attitudes and practices of doctors regarding IPT for patients infected with HIV at Odi Hospital in Gauteng.

Methods: A cross-sectional descriptive study was undertaken with a standardised questionnaire administered to 51 doctors working at Odi Hospital.

Results: There were 51 respondents, many doctors (43.1\%) having an excellent knowledge of IPT. Although one-third of the doctors were dispassionate about IPT provision, the majority of respondents (54.9\%) had positive attitudes towards IPT provision. On average the doctors had good practices regarding IPT provision (35.3\%). There were 12 (23.5\%) doctors who were trained for IPT implementation. Although training was not associated with doctors' knowledge or attitudes towards IPT, it was associated with the practice of IPT implementation.

Conclusion: Irrespective of their position, doctors at Odi District Hospital need formal training on the implementation of IPT, as this increases their confidence in IPT and their implementation practices.

Keywords: district hospital, HIV/AIDS, isoniazid preventive therapy, tuberculosis

\section{Introduction}

The World Health Organization (WHO) estimates that there are more than 1000 HIV-infected people dying every day from tuberculosis (TB). ${ }^{1}$ In 2015 the incidence of TB was 10.4 million cases worldwide and, of these, 1.2 million people were coinfected with HIV. During the same year, mortality from TB was 1.6 million people worldwide, with 400000 people coinfected with HIV. ${ }^{2}$ Africa is the continent with the highest prevalence of TB and HIV and $79 \%$ of TB patients living in Africa are HIV-positive. $^{2}$ In order to address the number of deaths caused by TB and HIV co-infection, the 'Three I's' strategy was proposed by the WHO: (i) intensify case findings, (ii) provide isoniazid preventive therapy (IPT), and (iii) control both infections. ${ }^{3}$ IPT provision has been successful in preventing new cases of TB in many countries. ${ }^{4}$

IPT is the administration of isoniazid (INH) to individuals with latent TB infection in order to prevent progression to active TB disease. INH is one of the most effective bactericidal anti-TB drugs available. INH not only protects against progression of latent TB infection to active disease, i.e. reactivation, but also prevents TB reinfection after exposure to an active case of TB. People living with HIV/AIDS (PLHIV) must be screened for TB using a four-symptom complex (current cough or fever or weight loss or night sweats) at HIV care settings, and those with any of these symptoms should be evaluated to rule out active TB. ${ }^{5}$
HIV-infected people are at a high risk of developing active TB, and are therefore provided with INH. It should, however, be confirmed that they do not have active TB before starting IPT. According to the WHO the risk of active TB in PLHIV can be reduced by up to $62 \%$ with the use of IPT. ${ }^{3}$ IPT may be provided as a safe, effective and feasible strategy for PLHIV in geographical regions with high rates of latent or highly active TB prevalence. ${ }^{5,6}$ When IPT is given for six months, the burden of TB on PLHIV is reduced from $67 \%$ to $33 \% .^{7}$ The SA IPT guidelines recommend at least 36 months of IPT for TST-positive HIV-infected persons, including people on ART; 6 months of IPT for those whose TST status is unknown, regardless of whether they are on ART or not; and 12 months of IPT for persons on ART if their TST is negative (NDOH, 2013). ${ }^{8}$ However, in a randomised control trial by Churchyard et al. (2014), ${ }^{9}$ it was found that a nine-month course of community-wide isoniazid preventive therapy did not improve tuberculosis control in South African gold mines. Continuous isoniazid preventive therapy should be considered for persons at highest risk for tuberculosis (i.e. those with HIV infection or silicosis) along with strategies to maximise retention. ${ }^{10}$

Jointly the United Nations Programme on HIV/AIDS (UNAIDS) and WHO made recommendations for the provision of IPT as a global strategy to reduce the incidence of TB for PLHIV. ${ }^{11}$ However, whilst there are 84 countries with clear policies on IPT, less than $1 \%$ of PLHIV in those countries are currently receiving IPT. ${ }^{12}$ 
Although TB is a global health problem, the prevalence of TB/HIV co-infection is highest in South Africa with approximately $65 \%$ of TB patients also living with HIV. ${ }^{13}$ Despite this fact, a recent study suggests that doctors are hesitant to prescribe IPT to TB-negative but HIV-infected patients. This contributes to the national TB epidemic. Substantial anecdotal evidence shows that doctors in South Africa have not been conforming to the WHO recommendations for prescribing IPT. ${ }^{1}$ In 2014, 1299 patients were initiated on antiretroviral therapy (ART) at Odi Hospital, but only 520 of these patients were initiated on IPT. A similar picture could be seen at the end of the third quarter of 2015 when 557 patients were initiated on ART, but only 295 were initiated on IPT. ${ }^{14}$ South African doctors either fear or are ignorant of IPT, despite IPT being recommended by the South African Department of Health. ${ }^{15}$

In Ethiopia lack of IPT implementation by healthcare providers was associated with the lack of opportunities for training on IPT and the unavailability of guidelines. Other reasons given by healthcare providers for not prescribing IPT were a lack of experience and not being aware of IPT efficacy. ${ }^{16}$ Although the WHO and South African National Department of Health issued key intervention guidelines and recommendations, the provision of IPT still lags behind in South Africa. Barriers preventing IPT implementation encompass a lack of training opportunities, fear of resistance to INH, unavailability of INH and INH's side effects. ${ }^{17}$

\section{Methodology}

This was a cross-sectional descriptive study that used a standardised self-administered questionnaire (see Appendix).

Odi district hospital is a level one hospital located in Mabopane, which is a border town in Gauteng province, $45 \mathrm{~km}$ north of Tshwane, South Africa. This is a 198-bed district hospital that serves a population of 524632 people from Gauteng province and 355905 people from North West province. The hospital has a large referral network of numerous clinics from both provinces, and is divided into service delivery units that include outpatients, emergencies, maternity, and a wellness clinic which cares only for TB and HIV/AIDS patients. It provides for the healthcare needs of children and adults around Odi health sub-district. ${ }^{14}$

Most of the clients of this hospital are poor and unemployed. There is a diversity of people, with mostly South African citizens and some immigrants from many African countries; the majority of immigrants are from Southern African Development Community countries.

Odi District Hospital employs an average of 51 doctors. ${ }^{14}$ All doctors working at Odi Hospital do rotate through the HIV clinic and hence all of them have encounters with TB and HIV/ AIDS patients and do manage these patients. Information was collected from all of the doctors between September 1, 2015 and March 31, 2016. The different categories of doctors attending to patients with TB and HIV/AIDS were seen as relevant to the study and were included. Doctors were briefly orientated as to the reasons for the study. Doctors who consented to participate in the study were provided with the questionnaire, which was given to them after the daily morning meeting. At least four doctors were able to complete their questionnaire each morning. A list of all participants' names was recorded on a separate sheet, and to ensure confidentiality this list was kept in a safe place that only the researcher had access to.
The data collection was by using standardised self-administered questionnaires and these were analysed using the SAS 9.0 software package (SAS Institute, Cary, NC, USA). Data were primarily analysed using descriptive statistics. A relationship between categorical variables was calculated using a chi-square test. Fisher's exact test was used to determine the association between knowledge, attitude and practices of doctors and their sociodemographic characteristics, with statistical significance set at $p<0.05$.

Permission to conduct this study was obtained from the Chief Executive Officer of Odi District Hospital. Data collection began after ethical clearance had been obtained from Sefako Makgatho Health Sciences University Research and Ethics Committee (SMUREC Ref. Number: SMUREC/M/202/2015; PG). Participation in the study was voluntary. Anonymity and confidentiality of the participants was maintained.

\section{Results}

All 51 doctors working at Odi District Hospital completed the questionnaire, a response rate of $100 \%$. This was achieved by meeting the doctors daily at the morning meetings to remind them of the study.

Table 1 gives demographic information on the participating doctors.

The response to each attitude statements by the doctors is given in Table 2. A total of 10 questions were asked in relation to the doctors' attitudes towards the efficacy and provision of IPT for PLHIV and nine of these questions were Likert scale options with positive statements ranging from strongly agree to strongly disagree.

Table 1: Doctors' sociodemographic characteristics

\begin{tabular}{|l|c|c|c|}
\hline Characteristics & Male & $\begin{array}{c}\text { Frequency } \\
(\boldsymbol{n}=\mathbf{5 1})\end{array}$ & $\begin{array}{c}\text { Percentage } \\
(\%)\end{array}$ \\
\hline Gender & Female & 30 & 58.8 \\
\hline \multirow{2}{*}{ Age group (years) } & $20-34$ & 18 & 41.2 \\
\hline & $35-49$ & 30 & 35.3 \\
\hline & $50-64$ & 2 & 58.8 \\
\hline & $65-79$ & 1 & 2 \\
\hline
\end{tabular}

Age: Mean $=38 \quad$ SD $=9.46 \quad$ Minimum $=23.00 \quad$ Maximum $=75.00$

\begin{tabular}{|l|c|c|c|}
\hline Professional category & $\begin{array}{c}\text { Community service } \\
\text { doctor }\end{array}$ & 7 & 13.7 \\
\hline & $\begin{array}{c}\text { Full-time medical } \\
\text { officer }\end{array}$ & 21 & 41.2 \\
\hline $\begin{array}{c}\text { Part-time medical } \\
\text { officer }\end{array}$ & 5 & 9.8 \\
\hline Registrar & 14 & 27.4 \\
\hline Experience (years) & Family physician & 4 & 7.8 \\
\hline & $\leq 9$ & 37 & 72.5 \\
\hline & $10-19$ & 8 & 15.7 \\
\hline $20-29$ & 3 & 5.9 \\
\hline
\end{tabular}

Experience: Mean $=9.2$ SD $=7.7 \quad$ Minimum $=1.0 \quad$ Maximum $=39.0$

\begin{tabular}{l|c|c|c|c|}
\hline $\begin{array}{l}\text { Additional formal } \\
\text { training on HIV/TB } \\
\text { management or IPT }\end{array}$ & $\begin{array}{c}\text { Training on TB and } \\
\text { HIV }\end{array}$ & 34 & 66.7 \\
\hline & $\begin{array}{c}\text { Training on IPT } \\
\text { No formal training }\end{array}$ & 12 & 23.5 \\
\hline & No forn & 9.8 \\
\hline
\end{tabular}


Each of the above responses was regrouped into three by combining strongly agree and agree to (i) agree, undecided remained as (ii) undecided and strongly disagree and disagree was combined as (iii) disagree. Each correct answer was scored one and a wrong answer scored zero. The total score out of nine was then multiplied by 100 to find the percentage score for the attitude level as listed in Table 5. The scores were classified into three levels as follows:

\begin{tabular}{|l|l|}
\hline Level & \multicolumn{1}{|c|}{ Definition } \\
\hline i. & Positive attitude: $\geq 75 \%$; \\
\hline ii. & Neutral attitude: $46 \%-74 \% ;$ \\
\hline iii & Negative attitude: $\leq 45 \%$. \\
\hline
\end{tabular}

Table 3 shows the doctors' response to the practice of IPT questions. Ten questions were asked relating to the practices of doctors regarding the implementation of IPT according to national guidelines. Five of the questions enquired about the frequency with which doctors provide IPT to PLHIV, also measuring their adherence to the national and WHO guidelines. These five questions had multiple-choice options ranging from 'Yes always', 'Sometimes' and 'No'. The other five questions were open-ended questions asking about interventions required for successful implementation of IPT in the working areas of the doctors.

Bloom's cut-off point ${ }^{18}$ was used to group the doctors' practice levels by measuring their provision of IPT and how its treatment management varied. The doctors' scores were from 0 to 5 . The levels of their practice were grouped as follows:

\begin{tabular}{l|l|}
\hline Level & \multicolumn{1}{|c|}{ Definition } \\
\hline i. & Excellent: $\geq 75 \%$; \\
\hline ii. & Good: $46 \%-74 \%$; \\
\hline iii & Poor: $\leq 45 \%$. \\
\hline
\end{tabular}

Table 4 shows the doctors' responses regarding individual knowledge of IPT. Doctors were asked a total of ten questions to explore their knowledge about IPT eligibility criteria, its management and IPT provision. One of the ten questions was openended to allow the doctors to express their ideas on the implementation of IPT at Odi District Hospital and the remaining nine questions were multiple-choice questions.

For each correct answer a mark was allocated and a percentage for the total marks was used to determine each doctor's
Table 3: Response to practice of IPT questions

\begin{tabular}{|l|c|c|c|}
\hline Practice question & $\begin{array}{c}\text { Yes, } \\
\text { always }\end{array}$ & Sometimes & No \\
\hline $\begin{array}{l}\text { 1. INH provision to HIV-positive } \\
\text { patients }\end{array}$ & $24(47.06)$ & $22(43.14)$ & $5(9.80)$ \\
\hline $\begin{array}{l}\text { 2. Management/monitoring of } \\
\text { patients with INH drug toxicity }\end{array}$ & $26(50.98)$ & $15(29.41)$ & $10(19.61)$ \\
\hline $\begin{array}{l}\text { 3. IPT eligibility is assessed with the } \\
\text { use of TB screening tool } \\
\text { (algorithm) as a criterion for PLHIV }\end{array}$ & $26(50.98)$ & $21(41.17)$ & $4(7.84)$ \\
\hline $\begin{array}{l}\text { 4. Advice is given to patients } \\
\text { regarding IPT adherence }\end{array}$ & $45(88.23)$ & $6(11.76)$ & $0(0.00)$ \\
\hline $\begin{array}{l}\text { 5. PLHIV are encouraged to start } \\
\text { IPT once eligible }\end{array}$ & $26(50.98)$ & $24(47.06)$ & $1(1.96)$ \\
\hline
\end{tabular}

knowledge. According to Bloom's taxonomy ${ }^{18}$ cut-off points, the scores were grouped into three levels according to correct answers, as listed in Table 5: Excellent: $\geq 75 \%$ correct; Good: $46 \%-74 \%$ correct; Poor: $\leq 45 \%$ correct.

The overall knowledge was good with a mean score of $66.5 \%$ $(S D=16.6)$. Most of the doctors $(43.1 \%)$ had excellent knowledge of IPT, whilst $37.3 \%$ had good knowledge and $19.6 \%$ poor knowledge of IPT.

A majority of the doctors (54.9\%) had positive attitudes towards IPT, only 6 doctors had negative attitudes, whilst 17 (33.3\%) were dispassionate about IPT provision. The global mean practice score of the doctors was $53.7 \%(\mathrm{SD}=23.7)$ : $13(25.5 \%)$ had excellent levels of practice, whilst $18(35.3 \%)$ showed good practice levels, and the remaining 20 (39.2\%) had poor practice levels with regard to IPT provision.

Table 6 gives the doctors' opinions of the barriers to successful implementation of IPT.

Comparison of possible associations between the knowledge, attitude, practices and sociodemographic characteristics of doctors was measured using Fisher's exact test. A $p$-value less than 0.05 was considered to be statistically significant.

There was no significant association between the doctors' experience and their knowledge, attitude and practices of IPT, as shown in Table 7.

Table 2: Response to each attitude statement

\begin{tabular}{|c|c|c|c|c|c|}
\hline Attitude statement & $\begin{array}{l}\text { Strongly } \\
\text { agree }\end{array}$ & Agree & Undecided & $\begin{array}{l}\text { Dis } \\
\text { agree }\end{array}$ & $\begin{array}{l}\text { Strongly } \\
\text { disagree }\end{array}$ \\
\hline $\begin{array}{l}\text { 1. The risk of INH resistance can be significantly reduced with use of IPT after active TB was } \\
\text { excluded. }\end{array}$ & 15.7 & 54.9 & 15.7 & 11.8 & 2.0 \\
\hline $\begin{array}{l}\text { 2. IPT should be provided to children aged less than one year with a household history of TB } \\
\text { case contact }\end{array}$ & 32.7 & 59.2 & 2.0 & 4.1 & 2.0 \\
\hline 3. Immune status in PLHIV should be a criterion for IPT eligibility & 11.8 & 54.9 & 5.9 & 25.5 & 2.0 \\
\hline $\begin{array}{l}\text { 4. IPT should be offered to PLHIV who don't have night sweats, weight loss fever and } \\
\text { current cough because they're unlikely to have active TB }\end{array}$ & 22.0 & 58.0 & 10.0 & 8.0 & 2.0 \\
\hline 5. You comply with national and international IPT recommendations & 13.7 & 51 & 21.6 & 13.7 & 0.0 \\
\hline 6. The reduction of TB mortality and incidence among PLHIV is effective by using IPT & 33.3 & 52.9 & 3.9 & 9.8 & 0.0 \\
\hline 7. Patients using IPT for longer periods have a reduced risk of TB & 21.6 & 39.2 & 15.7 & 19.6 & 3.9 \\
\hline 8. TB history is a contraindication for IPT provision & 28.0 & 50.0 & 10.0 & 12.0 & 0.0 \\
\hline 9. Pregnancy is a contraindication for IPT provision & 51.0 & 39.2 & 7.8 & 2.0 & 0.0 \\
\hline
\end{tabular}


Table 4: Doctors' responses to individual IPT knowledge questions

\begin{tabular}{|c|c|c|}
\hline Knowledge question & $\begin{array}{l}\text { Correct } \\
\text { answers }\end{array}$ & $\begin{array}{l}\text { Percentage } \\
(\%)\end{array}$ \\
\hline $\begin{array}{l}\text { 1. The INH drug dose used for } \\
\text { chemotherapy to prevent TB in an adult } \\
\text { living with HIV }\end{array}$ & 37 & 72.5 \\
\hline $\begin{array}{l}\text { 2. The combination of TB screening } \\
\text { symptoms identifies PLHIV for IPT eligibility }\end{array}$ & 45 & 88.2 \\
\hline $\begin{array}{l}\text { 3. IPT can be used as secondary } \\
\text { prophylaxis for people with a past history } \\
\text { of TB }\end{array}$ & 26 & 51 \\
\hline $\begin{array}{l}\text { 4. Pregnancy is a contraindication for IPT } \\
\text { eligibility }\end{array}$ & 43 & 84.3 \\
\hline 5. Assessment of patients' adherence to IPT & 34 & 66.7 \\
\hline 6. People eligible for IPT & 22 & 43.1 \\
\hline 7. The best preventative drug for TB & 46 & 90.2 \\
\hline $\begin{array}{l}\text { 8. TB infection in HIV-positive patients can } \\
\text { be reduced with the use of IPT }\end{array}$ & 43 & 84.3 \\
\hline $\begin{array}{l}\text { 9. IPT eligibility is characterised by using } \\
\text { chest radiography as a requirement for } \\
\text { PLHIV screening }\end{array}$ & 26 & 51 \\
\hline
\end{tabular}

The $p$-value of 0.2986 indicates there was no statistically significant association between doctors' knowledge and attitude; however, $47 \%(n=24)$ of the doctors with good and excellent knowledge scores also had a positive attitude towards IPT, as shown in Table 8.

There was no statistically significant association between knowledge and practice of the doctors towards IPT provision, with the $p$-value being 0.7352 (see Table 6). There is a significant association between the doctors' attitude and the practice of IPT, with a $p$-value of 0.0185 , as shown in Table 9.

The results in Table 9 indicated that there is no statistical significance between training for IPT implementation and doctors'

Table 5: Composite doctors' knowledge, practices and attitude towards IPT

\begin{tabular}{|c|c|c|}
\hline Knowledge & Number & Percentage \\
\hline Excellent ( $\geq 75 \%$ ) & 22 & 43.14 \\
\hline Good (46-74\%) & 19 & 37.25 \\
\hline Poor $(\leq 45 \%)$ & 10 & 19.61 \\
\hline Total & 51 & 100 \\
\hline $\begin{array}{l}\text { Knowledge: } \text { mean }=66.5 \quad S D=16.6 \\
100.0\end{array}$ & Minimum $=33.3$ & Maximum = \\
\hline Knowledge: mean $=66.5$ & $\mathrm{SD}=16.6$ & \\
\hline Level of practice & Number & Percentage (\%) \\
\hline Excellent ( $\geq 75 \%)$ & 13 & 25.49 \\
\hline Good (46-74\%) & 18 & 35.29 \\
\hline Poor $(\leq 45 \%)$ & 20 & 39.21 \\
\hline Total & 51 & 100 \\
\hline Practice: mean = 53.7 & \multicolumn{2}{|c|}{ Minimum $=0 \quad$ Maximum $=100$} \\
\hline Attitude score & \begin{tabular}{l|l} 
Number & \\
\end{tabular} & Percentage (\%) \\
\hline Positive ( $\geq 75 \%$ ) & 28 & 54.90 \\
\hline Neutral (46-74\%) & 17 & 33.33 \\
\hline Negative ( $\leq 45 \%)$ & 6 & 11.76 \\
\hline Total & 51 & 100.0 \\
\hline Attitude: mean $=71.7$ & Minimum $=33.3$ & Maximum $=100.0$ \\
\hline
\end{tabular}

Table 6: Barriers to successful implementation of IPT

\begin{tabular}{|l|c|c|}
\hline Barrier & Number & Percentage (\%) \\
\hline Lack of doctor's knowledge of IPT & 19 & 37.3 \\
\hline Fears of INH resistance & 8 & 15.7 \\
\hline Poor patient adherence & 17 & 33.3 \\
\hline Unavailability of INH & 7 & 13.7 \\
\hline Total & 51 & 100 \\
\hline
\end{tabular}

knowledge or attitude, but that there is an association with doctors' practices regarding IPT provision, as evidenced by a $p$-value of 0.0185 .

\section{Discussion}

When considering the demographic characteristics of this sample, most (89.5\%) of the respondents were in the age group 22-40 years. In this regard, our results can be compared to a study where the context was similar. ${ }^{19}$ More than half or $34(66.7 \%)$ of the doctors had received formal training in managing patients with TB/HIV co-infection, and only 12 (23.5\%) were trained on the IPT implementation programme.

Many doctors (22 or $43.1 \%$ ) had excellent knowledge regarding the provision of IPT. These findings are in contrast with a large study done in Ethiopia, which indicated that efficient IPT implementation in that country was hindered by the healthcare providers' poor knowledge of IPT. ${ }^{20}$ The high score in our study is most likely due to the formal training they received on TB/HIV and IPT. These findings are supported by a study conducted in Brazil, which reported that IPT training resulted in significantly increased knowledge of and prescription of IPT. ${ }^{21}$

The barriers to IPT implementation were reported by $37.3 \%$ of the doctors to be a lack of IPT knowledge and the possibility of poor patient adherence to IPT (33.3\%). The most common researched barriers to IPT implementation are doctors' attitudes and beliefs. ${ }^{15}$ A study in Thailand also found that doctors' fear of lack of patient adherence to IPT was a very common reason for their unsuccessful IPT implementation programme. ${ }^{22}$ A South African study reported that patient adherence was not a concern for healthcare workers in prescribing IPT. ${ }^{20}$ Thus it seems that doctors' knowledge of IPT and perceived poor adherence by patients due to possible side effects are barriers that can be overcome in South Africa, by training and effective implementation of the programme.

The fear of generating drug resistance was the third most common barrier to IPT implementation. This finding correlated with findings of a cross-sectional survey conducted by the WHO in 69 high-burden countries in 2007, which affirmed that doctors are sceptical of providing IPT despite efforts to exclude active TB and inadequate TB case findings. ${ }^{23}$

Unsuccessful provision of IPT by physicians was associated with inducing INH resistance in Thailand. ${ }^{24} \mathrm{~A}$ systematic review assessing the effect of IPT on risk of INH-resistant TB reported that IPT increased the risk of INH resistance 1.45 times; this was not significant (relative risk 1.45; 95\% confidence interval 0.85-2.47). The increased risk of INH-resistant TB is not excluded because of the relative risk and also because of the relatively small sample size, and the analysis was limited. ${ }^{25}$ The consensus from current literature is that IPT does not promote INH resistance. $^{26,27}$ 
Table 7: Relationship between doctors' experience and knowledge, attitude and IPT practices

\begin{tabular}{|c|c|c|c|c|c|c|}
\hline \multirow[b]{2}{*}{ Knowledge of IPT } & \multicolumn{4}{|c|}{ Experience (years) } & \multirow[b]{2}{*}{ Total } & \multirow[b]{2}{*}{$p$-value } \\
\hline & $\leq 9$ & $10-19$ & $20-29$ & $30-39$ & & \\
\hline Excellent & $17(33.3)$ & $3(5.9)$ & 0 & $2(3.9)$ & $22(43.1)$ & \multirow[t]{4}{*}{0.2041} \\
\hline Good & $12(23.5)$ & $4(7.8)$ & $3(5.9)$ & 0 & $19(37.3)$ & \\
\hline Poor & $8(15.7)$ & $1(2)$ & 0 & $1(2)$ & $10(19.6)$ & \\
\hline Total & $37(72.5)$ & $8(15.7)$ & $3(5.9)$ & $3(5.9)$ & $51(100)$ & \\
\hline \multicolumn{7}{|l|}{ Attitude: } \\
\hline Positive & $20(39.2)$ & $5(9.8)$ & $3(5.9)$ & 0 & $28(54.9)$ & \multirow[t]{4}{*}{0.3335} \\
\hline Neutral & $13(25.5)$ & $2(3.9)$ & 0 & $2(3.9)$ & $17(33.3)$ & \\
\hline Negative & $4(7.8)$ & $1(2)$ & 0 & $1(2)$ & $6(11.8)$ & \\
\hline Total & $37(72.5)$ & $8(15.7)$ & $3(5.9)$ & $3(5.9)$ & $51(100)$ & \\
\hline \multicolumn{7}{|l|}{ Practice: } \\
\hline Excellent & 9 (17.6) & $2(3.9)$ & $2(3.9)$ & 0 & $13(25.5)$ & \multirow[t]{4}{*}{0.5615} \\
\hline Good & $12(23.5)$ & $3(5.9)$ & $1(2)$ & $2(3.9)$ & $18(35.3)$ & \\
\hline Poor & $16(31.4)$ & $3(5.9)$ & 0 & $1(2)$ & $20(39.2)$ & \\
\hline Total & $37(72.5)$ & 8 (15.7) & $3(5.9)$ & $3(5.9)$ & $51(100)$ & \\
\hline
\end{tabular}

Table 8: Relationship between doctors' knowledge, attitude and IPT practice

\begin{tabular}{|c|c|c|c|c|c|}
\hline \multirow[b]{2}{*}{ Knowledge of IPT } & \multicolumn{3}{|c|}{ Attitude } & \multirow[b]{2}{*}{ Total } & \multirow[b]{2}{*}{$p$-value } \\
\hline & Positive $n(\%)$ & Neutral $n(\%)$ & Negative $n(\%)$ & & \\
\hline Excellent & $11(21.6)$ & $9(17.7)$ & $2(3.9)$ & $22(43.1)$ & \multirow[t]{4}{*}{0.2986} \\
\hline Good & $13(25.5)$ & $5(9.8)$ & $1(2)$ & $19(37.3)$ & \\
\hline Poor & $4(7.8)$ & $3(5.9)$ & $3(5.9)$ & $10(19.6)$ & \\
\hline Total & $28(54.9)$ & $17(33.3)$ & $6(11.8)$ & $51(100)$ & \\
\hline \multirow[t]{2}{*}{ Knowledge of IPT } & \multicolumn{3}{|c|}{ Practice } & & \\
\hline & $\begin{array}{c}\text { Excellent } \\
n(\%)\end{array}$ & Good $n(\%)$ & Poor $n(\%)$ & & \\
\hline Excellent & $4(7.8)$ & $8(15.7)$ & $10(19.6)$ & $22(43.2)$ & \multirow[t]{4}{*}{0.7352} \\
\hline Good & $7(13.7)$ & $6(11.8)$ & $6(11.8)$ & $19(37.2)$ & \\
\hline Poor & $2(3.9)$ & $4(7.8)$ & $4(7.8)$ & $10(19.6)$ & \\
\hline Total & $13(25.5)$ & $18(35.3)$ & $20(39.2)$ & $51(100)$ & \\
\hline Attitude & \multicolumn{4}{|c|}{ Practice } & \\
\hline Positive & $12(23.5)$ & $6(11.8)$ & $10(19.6)$ & $28(54.9)$ & \multirow[t]{4}{*}{0.0185} \\
\hline Neutral & $1(2)$ & 9 (17.6) & $7(13.7)$ & $17(33.3)$ & \\
\hline Negative & 0 & $3(5.9)$ & $3(5.9)$ & $6(11.8)$ & \\
\hline Total & $13(25.5)$ & $18(35.3)$ & $20(39.2)$ & $51(100)$ & \\
\hline
\end{tabular}

The findings with regard to doctors' attitudes towards IPT were consistent with a study where the mean attitude score of healthcare workers towards IPT was $80.6 \%$, with $69.2 \%$ having a positive attitude, $26.9 \%$ a neutral attitude score, and $3.9 \%$ a negative attitude score ${ }^{19}$ Healthcare workers' favourable attitude (60\%) towards IPT provision was also reported in a study conducted in Indonesia. ${ }^{26}$ In the current study, the majority (33; 64.7\%) believed they comply with the national and international recommendations of IPT guidelines. Whilst this level of compliance by the doctors with the national and international recommendation guidelines is highly commendable, it could be improved. The attitudes with regard to compliance contrast to those in a study conducted in the Bojanala district of North West province of South Africa, which reported a low overall adherence rate by doctors to the treatment guidelines of $51 \%{ }^{28}$ A systematic review of 76 published articles also concluded that doctors generally adhered poorly to clinical practice guidelines, ${ }^{29}$ in contrast with the findings of the current study.

Remarkably, most doctors 45 (88.2\%) advised their patients on adherence to IPT. Patient adherence was self-reported by 79.9\% of patients in Addis Ababa, and this was reported to be associated with healthcare providers giving adequate information to their patients. ${ }^{30}$ In contrast, in a previous study conducted in Addis Ababa, patient non-adherence was observed due to insufficient information regarding IPT provided by the healthcare providers. ${ }^{31}$ Healthcare providers' adherence to HIV and TB guidelines for treatment and detection of latent TB amongst PLHIV was very poor, and physicians' adherence to guidelines was associated with their experience. ${ }^{32}$ 
Table 9: Relationship between doctors trained on IPT and knowledge, attitude and IPT practice

\begin{tabular}{|c|c|c|c|c|}
\hline \multirow[b]{2}{*}{$\begin{array}{l}\text { Knowledge } \\
\text { of IPT }\end{array}$} & \multicolumn{2}{|c|}{ Received IPT training } & \multirow[b]{2}{*}{$\begin{array}{l}\text { Total } \\
n(\%)\end{array}$} & \multirow[b]{2}{*}{$p$-value } \\
\hline & $\begin{array}{l}\text { Yes } \\
n(\%)\end{array}$ & $\begin{array}{c}\text { No } \\
n(\%)\end{array}$ & & \\
\hline Excellent & $7(13.7)$ & $15(29.4)$ & $22(43.1)$ & \multirow[t]{4}{*}{0.1323} \\
\hline Good & $5(9.8)$ & $14(27.4)$ & $19(37.3)$ & \\
\hline Poor & 0 & $10(19.6)$ & 10 (19.6) & \\
\hline Total & $12(23.5)$ & $39(76.5)$ & $51(100.0)$ & \\
\hline \multicolumn{5}{|l|}{ Attitude: } \\
\hline Positive & $7(13.7)$ & $21(41.2)$ & $28(54.9)$ & \multirow[t]{4}{*}{1.0000} \\
\hline Neutral & $4(7.8)$ & $13(25.5)$ & $17(33.3)$ & \\
\hline Negative & $1(2)$ & $5(9.9)$ & $6(11.8)$ & \\
\hline Total & $12(23.5)$ & $39(76.5)$ & $51(100)$ & \\
\hline \multicolumn{5}{|l|}{ Practice: } \\
\hline Excellent & $6(11.8)$ & $7(13.7)$ & $13(25.5)$ & \multirow[t]{4}{*}{0.0185} \\
\hline Good & $2(3.9)$ & $16(31.4)$ & $18(35.3)$ & \\
\hline Poor & $4(7.8)$ & $16(31.4)$ & $20(39.2)$ & \\
\hline Total & $12(23.5)$ & $39(76.5)$ & $51(100.0)$ & \\
\hline
\end{tabular}

There was no statistically significant association $(p=0.2986)$ between the knowledge of doctors and their attitudes towards IPT provision in this study. In contrast, another study indicated that healthcare providers' attitudes had a significant association with knowledge $(p<0.001)$.

There was no statistically significant association between the knowledge and practice of doctors $(p=0.735)$. Only four (7.8\%) doctors had excellent knowledge coupled with excellent practice. Ten (19.6\%) doctors with excellent knowledge had poor practice levels. There is strong evidence that TB-related training is a positive predictive factor for practice. ${ }^{33}$

The doctors' attitude had a highly significant association with the level of doctors' practice behaviour towards IPT provision. As the level of attitude increases, the practice of IPT amongst doctors in Odi District Hospital improves. Hence training and awareness programmes should be emphasised, to increase the positive attitude of doctors towards IPT implementation as supported by Durovin et al., who conducted a TB/HIV study in Rio de Janeiro, the results of which strongly supported the importance of the training and education of staff in health units regarding IPT intervention. ${ }^{21}$

Overall the formal training on IPT had a statistically significant association with the practice of IPT. This finding supports that of an earlier large study, which suggested that training led to an observed rapid increase in IPT implementation in HIV-positive patients. $^{34}$

\section{Conclusion}

Doctors at Odi District Hospital generally had excellent knowledge of IPT, but this was not reflected in their practice, as their mean practice score was just above an average of $50 \%$. Although most doctors were not trained on IPT, their attitude scores were high; only $12(23.5 \%)$ of the doctors were trained on the IPT programme and implementation. The finding that healthcare providers' lack of information (35\%) did not comply with the national and international IPT recommendations was evident in other studies. ${ }^{31}$ These could be the reasons for the low level of IPT provision at Odi District Hospital.
As a result, it can be concluded that doctors in Odi District Hospital, irrespective of their category, need formal training specifically in IPT and its successful implementation at the hospital.

\section{Limitation of the study}

The study has a descriptive design and does not attempt to generalise the findings to populations outside the study participants. Therefore, the findings of this study could not be generalised beyond the participants at Odi Hospital. The results of this study may not necessarily apply to other contexts although the authors believe that this may be the case for most district hospitals. This research did not explore other means of preventing TB such as vaccines.

\section{Disclosure statement}

No potential conflict of interest was reported by the authors.

\section{ORCID}

AT Abdulrazaak (D) http://orcid.org/0000-0002-8735-8982

\section{References}

1. World Health Organization. WHO fact sheet; global tuberculosis report 2014. Geneva: WHO; 2014.

2. World Health Organization. WHO 2016 global report on country profiles for the 30 high- burden countries for tuberculosis. Geneva: WHO; 2016.

3. World Health Organization. WHO three I's meeting. Intensified Case Finding, Isoniazid Preventive Therapy and TB Infection Control for people living with HIV. Report of a joint WHO HIV/AIDS and TB Department Meeting, 2-4 April. Geneva: WHO; 2008.

4. Gupta A, Wood R, Kaplan R, et al. Tuberculosis incidence rates during 8 years of follow-up of an antiretroviral treatment cohort in South Africa: comparison with rates in the community. PLOS One. 2012;7 (3):e34156. https://doi.org/10.1371/journal.pone.0034156

5. Naidoo K, Padayatchi N, Karim QA. HIV-associated tuberculosis. Clin Dev Immunol. 2011: 585919. doi:10.1155/2011/585919.

6. Granich R, Crowley S, Vitoria M, et al. Highly active antiretroviral treatment for the prevention of HIV transmission. J Int AIDS Soc. 2010;5 (4):298-304.

7. World Health Organization. Toward universal access: scaling up priority HIV/AIDS interventions in the health sector: progress report. Geneva: WHO; 2010.

8. National Department of Health. South Africa. Guidelines for tubercu losis preventive therapy among HIV-infected individuals in South Africa. 2013.

9. Churchyard GJ, Gavin K, Katherine L, et al. Trial of mass isoniazid preventive therapy for tuberculosis control. N Engl J Med. 2014;370 301-310. doi:10.1056/NEJMoa1214289.

10. Martinson NA, Barnes GL, Moulton LH, et al. New regimens to prevent tuberculosis in adults with HIV infection. N Engl J Med. 2011;365: 11-20. 9

11. Godfrey-Fausett P. Policy statement of preventive therapy against tuberculosis in people living with HIV. Report of a meeting held in Geneva, 18-20 February 1998. World Health Organization, Global Tuberculosis Programme and UNAIDS [Internet]. Geneva: WHO 1998. Available from: http://whqlibdoc.who.int/hq/1998/WHO_TB_ 98.255.pdf.

12. Mosimaneotsile $B$, Mathoma $A$, Chengeta $B$, et al. Isoniazid tuberculosis preventive therapy in HIV-infected adults accessing antiretroviral therapy: a Botswana experience, 2004-2006. J Acq Immune Defic Synd. 2010;54(1):71-77.

13. World Health Organization. Global tuberculosis report 2013. Geneva: WHO; 2013.

14. Odi District Hospital Records. (2015.

15. Bateman C. Doctor IPT ignorance contributing to TB epidemic: study. SAMJ. 2011;101(2):88-90.

16. Churchyard GJ. Doctor IPT ignorance contributing to TB epidemic study. SAMJ. 2011;104(5):88-90.

17. Teklay G, Teklu T, Legesse B, et al. Barriers in the implementation of isoniazid preventive therapy for people living with HIV in northern 
Ethiopia: a mixed quantitative and qualitative study. BMC Public Health. 2016;16:3525-3528.

18. Bloom BS, Engelhart MD, Fusrt EJ, et al. Taxonomy of educational objectives: the classification of educational goals. handbook 1: cognitive domain. New York: David McKay Company; 1959.

19. Pontali E, Matteelli A, Migliori GB. Drug-resistant tuberculosis. Curr Opin Pulm Med. 2013;19(3):266-72.

20. Tikuye AM. Knowledge, attitudes and practices of health care providers towards isoniazid preventive therapy provision in Addis Ababa, Ethiopia [Master's of Public Health dissertation]. University of South Africa; 2013.

21. Durovni B, Cavalcante SC, Saraceni V, et al. The implementation of isoniazid preventive therapy in HIV clinics: the experience from the TB/HIV in Rio (THRio) study. AIDS. 2010;24(Supplement 5):S49-S56.

22. Hiransuthikul N, Hiransuthikul P, Nelson EK, et al. Physician adherence to IPT. South-east Asian J Trop Med Public Health. 2005;36 (5):1208-1215.

23. Lester R, Hamilton R, Charalambous $\mathrm{S}$, et al. Barriers to implementation of isoniazid preventive therapy in HIV clinics: a qualitative study. AIDS. 2010;24(5):45-48.

24. Date AA, Vitoria $M$, Granich $R$, et al. Implementation of co-trimoxazole prophylaxis and isoniazid preventive therapy for people living with HIV. Bull WHO. 2010;88(4):253-259.

25. Balcells ME, Thomas SL, Godfrey-Faussett P, et al. Isoniazid preventive therapy and risk for resistant tuberculosis. Emerg Infect Dis. 2006;12 (5):744-751.

26. Charalambous S, Grant AD, Innes C. Association of isoniazid preventive therapy with lower early mortality in individuals on antiretroviral therapy in a workplace programme. AIDS. 2010;24(Suppl 5): S5-S13.
27. Sutiono HO, Soeroto AY, Lestari BW. Knowledge, attitude and practice survey among nurses in $\mathrm{Dr}$ hasan sadikin general hospital towards tuberculosis human immunodeficiency virus collaboration program. Althea Med J. 2016;3(1):85-92.

28. Adedeji AR, Tumbo J, Govender I. Adherence of doctors to a clinical guideline for hypertension in bojanala district, north west province, South Africa. PHCFM. 2015;7(1):776. doi:10.4102/phcfm.v7i1.776.

29. Cabana MD, Rand CS, Powe NR, et al. Why don't physicians follow practice guidelines? A framework for improvement. JAMA. 1999;282(15):1458-1465.

30. Mindachew M, Deribew A, Tessema F, et al. Predictors of adherence to isoniazid preventive therapy among HIV positive adults in Addis Ababa, Ethiopia. BMC Public Health. 2011;11:1-7.

31. Mindachew $M$, Deribew $A$, Memiah $P$, et al. Perceived barriers to the implementation of isoniazid preventive therapy for people living with HIV in resource constrained settings: a qualitative study. Pan Afr Med J. 2014;17:26. doi:10.11604/pamj.2014.17.26.2641

32. Saraceni V, King BS, Golub JE, et al. Tuberculosis as primary cause of death among AIDS cases in Rio de janeiro city, Brazil. Int J Tuberc Lung Dis. 2008;12:769-772.

33. Gigaw GD, Alemu ZA, Tihahun K. Assessment of knowledge and practice of health workers towards tuberculosis infection and control and associated factors in public health facilities of Addis Ababa, Ethiopia: a cross-sectional study. Arch Public Health. 2015;73:15-24.

34. Bristow CC, Larson E, Vilakazi-Nhlapo AK, et al. Scale-up of isoniazid preventive therapy in PEPFAR-assisted clinical sites in South Africa. Int J Lung Dis. 2012;16(8):1020-1022.

Received: 16-12-2017 Accepted: 13-11-2018 


\section{Appendix A: Questionnaire}

\section{A. Demographic information}

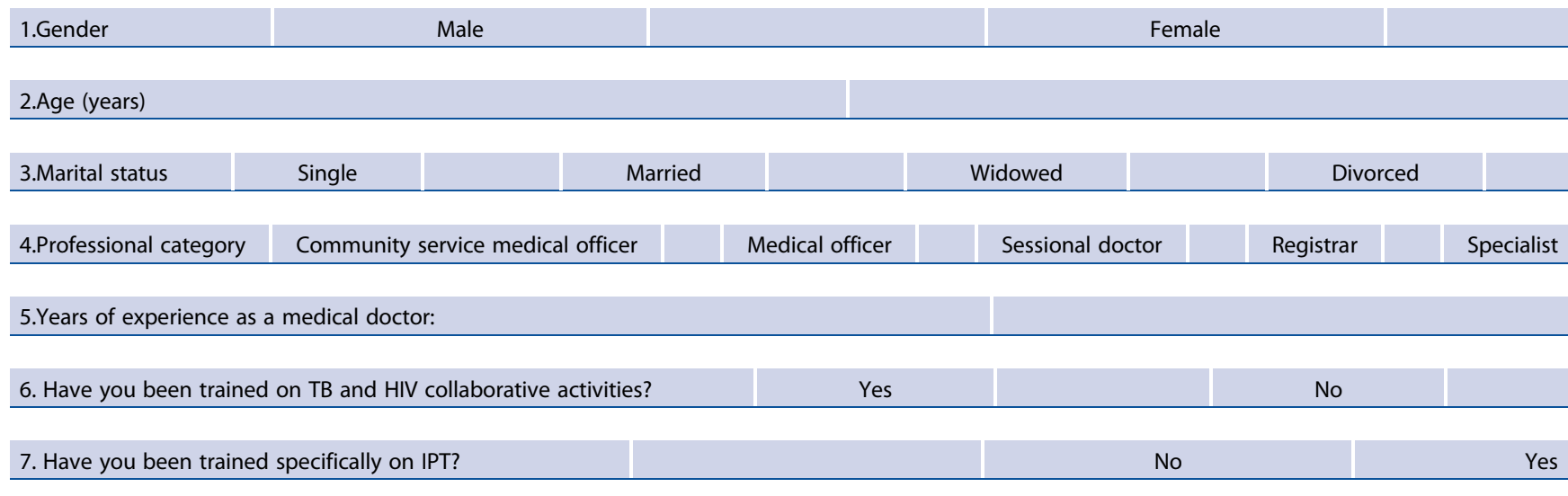

\section{B. Knowledge about IPT}

Please tick or circle one of your best answers as appropriate to the specific item of the question.

8. In your opinion, do you think IPT reduces the risk of TB infection in HIV-positive patients?

Yes

No

9. Which combination of TB screening symptoms do you use to identify whether PLHIV are eligible for IPT or 1. Current cough, rash, fever, weight loss.
$\begin{aligned} & \text { not? } \\ & 2 \text {. Fever, current cough, rash, night sweats. } \\ & 3 \text {. Current cough, fever, night sweats, weight } \\ & \text { loss. } \\ & 4 \text {. Weight loss, nausea, fever, rash. }\end{aligned}$

10. Do you think chest radiography is a requirement for screening PLHIV for IPT eligibility? Yes

No

11.In your opinion, who is eligible to receive IPT

1. All infants of mother with pulmonary TB.

2. All infants $<5$ years in contact with smear-positive TB patient.

3. All HIV positive patients who do not have active TB.

4. All above cases.

5. Only 2 and 3.

12. Do you think current pregnancy is a contraindication for starting IPT?

Yes

No

13. Can IPT be used as secondary prophylaxis for people with past history of TB?

Yes

No

14. Which is the best TB preventive drug?
1. Isoniazid (INH)
2. Rifampicin (RIF)
3. Pyrizinamide (PZA)
4. None

15. What is the INH drug dose used for chemotherapy to prevent TB in adults living with HIV?
1. $100 \mathrm{mg} / \mathrm{day}$
2. $200 \mathrm{mg} /$ day
3. $300 \mathrm{mg} / \mathrm{day}$
4. $150 \mathrm{mg} / \mathrm{day}$
5. None of the above.

3. Pill counts.

4. Pharmacy refill data. 
5. All above.

6. None of the above.

17. In your opinion, mention the major barriers for successful implementation of IPT in your area.

1.

2.

3.

6.

\section{Attitude towards IPT efficacy and provision}

Please select only one response that best suits among the Likert scale measurement of your attitude.

18. IPT is effective in reducing TB incidence and mortality among PLHIV.

1. Strongly agree.

2. Agree.

3. Undecided.

4. Disagree.

5. Strongly disagree.

19. PLHIV who do not have current cough, fever, weight loss or night sweats are unlikely to have active TB and should be offered IPT.
2. Agree.
3. Undecided.
4. Disagree.
5. Strongly disagree.

20. IPT should be given to all eligible PLHIV irrespective of their immune status.

1. Strongly agree.

2. Agree.

3. Undecided.

4. Disagree.

5. Strongly disagree.

21. After excluding active TB, IPT won't significantly increase the risk of developing INH resistance.

1. Strongly agree.

2. Agree.

3. Undecided.

4. Disagree.

5. Strongly disagree.

22. Children < 1year of age should be provided with IPT if they have a household contact history with a TB case.

1. Strongly agree.

2. Agree.

3. Undecided.

4. Disagree.

5. Strongly disagree.

23. Pregnancy is not a contraindication for IPT provision.

1. Strongly agree.

2. Agree.

3. Undecided.

4. Disagree.

5. Strongly disagree.

3. Undecided.

4. Disagree.

5. Strongly disagree. 
25. The longer the duration of IPT ( $>6$ months), the longer the patient stays free from TB.

1. Strongly agree.

2. Agree.

3. Undecided.

4. Disagree.

5. Strongly disagree.

26. On overall, do you agree that you are complying with the national and international IPT recommendations?

1. Strongly agree.

2. Agree.

3. Undecided.

4. Disagree.

5. Strongly disagree.

27. If not agreeing to the above, mention your major beliefs preventing you from complying with the recommendations.

2.

3.

4.

5 .

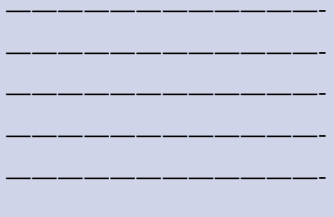

\section{Practice on IPT provision}

28. Do you use the TB screening tool (algorithm) to identify PLHIV eligible for IPT?

1. Yes, always.

2. Yes, sometimes.

3. No.

29. Do you encourage PLHIV to start IPT once they are eligible?

1. Yes, always.

2. Yes, sometimes.

3. No.

30. Do you provide INH for eligible HIV-positive patients?

1. Yes, always.

2. Yes, sometimes.

3. No.

31. If your answer for Q30 is yes, how many of the 10 newly enrolled HIV-positive patients started IPT in the last one year? IPT.

32. If you are providing IPT for your patients, how frequently do you supply the INH drug?
1. Daily.
2. Weekly.
3. Monthly.
4. Every 3 months.
5. Per patient's convenience.

33. Do you advise clients on IPT to adhere to their treatment?

1. Yes, always.

2. Yes, sometimes.

3. No.

34. Do you monitor/manage clients with INH drug toxicity?

1. Yes, always.

2. Yes, sometimes.

3. No. 


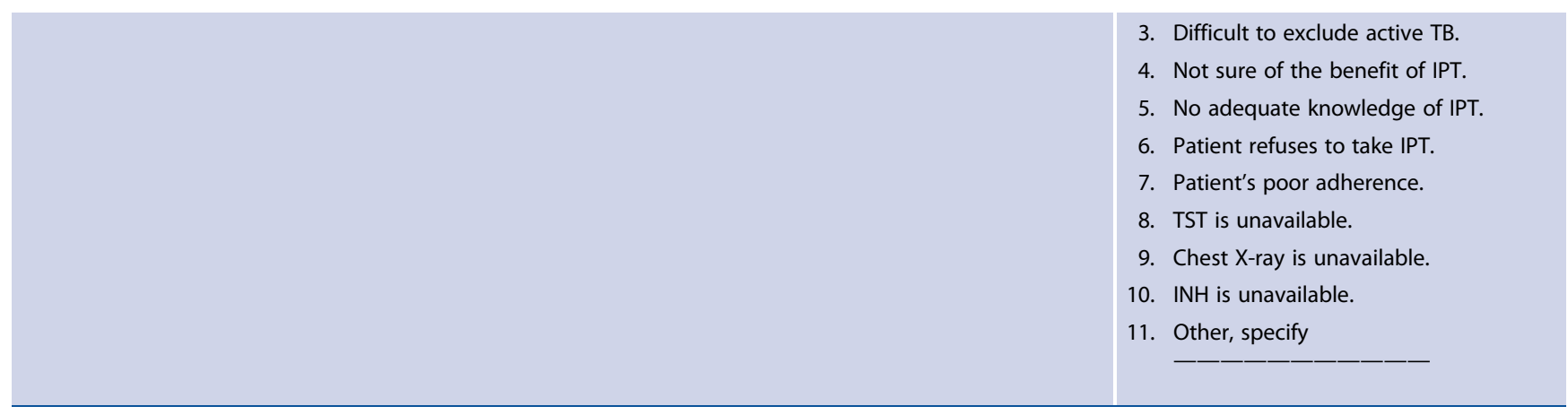

36. Did you experience INH stock out in the last one year?

37. Please mention the major interventions required for the successful implementation of IPT in your area.
1. Yes, for less than one month.

2. Yes, for more than one month.

3. No shortage.

4. N/A
1.

2.

3.

4.

5. 